prednisolone $(30 \mathrm{mg} / \mathrm{kg})$ for 3 days was given in 27 patients. Two patients received hydrocortisone in SJIA MAS secondary to infections (chickenpox, Hepatitis A). In patients unresponsive to steroids IVIG and/or cyclosporine was used. $19(65 \%)$ patients survived whereas $10(35 \%)$ died. Of the 10 who succumbed, the $\mathrm{HLH} 2004$ protocol (including etoposide) was used in 2 who were refractory to pulse methylprednisolone +cyclosporine +IV Ig, but without any success. 2 patients on Tocilizumab had silent MAS.

Ferritin $>50000 \mathrm{ng} / \mathrm{ml}$ was seen in 11 patients of which 8 died. Chi square test of significance was done and $p$ value $(0.001)$ was significant for mortality in patients with ferritin $>50000 \mathrm{ng} / \mathrm{ml}$, with a positive correlation (0.613).

Patients with cardiovascular involvement especially pericardial effusion in SJIA was observed to have higher mortality but no statistical correlation could be made Conclusions: MAS is a fatal complication with a high mortality rate of $35 \%$ in our series. Ferritin levels $>50,000 \mathrm{ng} / \mathrm{ml}$ was associated with high mortality. Early and aggressive intervention with optimal intensive care support maybe life saving

Disclosure of Interest: None declared

DOI: 10.1136/annrheumdis-2018-eular.3951

\section{AB1117 ISOLATED CERVICAL ARTHRITIS AS THE SOLE MANIFESTATION OF FAMILIAL MEDITERRANEAN FEVER: A CASE REPORT}

R. Dagher ${ }^{1}$, M. Samarani ${ }^{1}$, A. Chelala ${ }^{2}$, M.C. Fadous Khalife ${ }^{1} .{ }^{1}$ pediatrics;

${ }^{2}$ radiology, Notre Dame de Secours University Hospital, Byblos, Lebanon

Background: Familial Mediterranean Fever (FMF) is an autosomal recessive disease affecting mainly eastern Mediterranean populations. Fever and Abdomina pain are the 2 most prevalent features. The most common arthritic manifestation of FMF is acute self-limiting monoarthritis. $5 \%$ of FMF patients develop chronic erosive arthritis. FMF mutation M694V has been associated to an increased risk of spondylarthropathy.

Objectives: We report the case of a child with cervical spine inflammation as the sole presentation of FMF.

Methods: A boy born to non-consanguineous parents presented at the age of 4 with complete blockage of his neck. He was described to have experienced progressive neck stiffness since the age of 3 years. His history is notable for intermittent limp at the age of 1 with complete spontaneous remission, and possible recurrent fever in the first 2 years of life. Family history is negative.

His physical exam revealed a painful and completely blocked neck in all movements, and stubby fingers. He had failure to thrive and a big belly without hepatos plenomegaly. Cognitive development was normal.

Laboratory tests revealed increased inflammatory markers. Other biological tests were insignificant. ANA, RF, anti-CCP and HLA B27 were negative. Lysosomal enzyme activities were normal ruling out muccopolysacharidosis, mucolipidoses and multiple sulfatase deficiencies. Work-up for failure to thrive was noncontributory. Ophtalmic screening showed no abnormalities.

Cervical spine plain radiographs were normal. Cervical MRI showed global contrast enhancement of cervical vertebrae and joints with blurring of the osseous contours and synovial inflammation; bone oedema was noted and involved some posterior arcs, spinous processes and pedicules. Sacro-iliac MRI was normal. The child was treated with oral steroids along with methotrexate and etanercept secondarily due to steroid dependance. Inflammatory markers normalised and clinical improvement was noted as the range of motion of neck increased and pain subsided. Repeated MRI after 6 months showed an almost normal image.

Results: Given this atypical isolated inflammation of the cervical spine, genetic testing for FMF was conducted. We identified 2 typical mutations (M694V and M694I) confirming the diagnosis of FMF. Colchicine treatment was started.

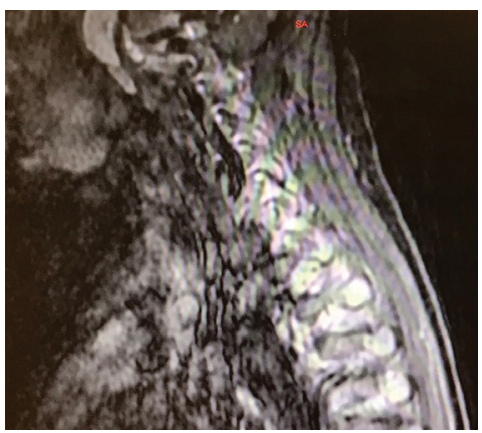

Abstract AB1117 - Figure

Conclusions: To the best of our knowledge, this is the first report of FMF masquerading as neck arthritis. Early spondylarthropathy is a possibility, but this unusual neck inflammation might be an isolated arthritis associated to FMF. Based on this clinical presentation, in the setting of atypical arthritis, diagnosis of FMF is to be raised in at-risk ethnicities, even in the absence of familial history and common clinical signs.

\section{REFERENCES}

[1] Sönmez HE,Batu ED,Demir S,Bilginer Y,Özen S. Comparison of patients with familial Mediterranean fever accompanied with sacroiliitis and patients with juvenile spondyloarthropathy. Clinical and Experimental Rheumatology. 2017 Nov-Dec;35 Suppl 108(6):124-127

[2] Younes M,Kahn MF,Meyer O. Hip involvement in patients with familial Mediterranean fever. A review of ten cases. Joint Bone Spine. 2002 Dec;69(6):560-5.

[3] Güncan S, Bilge NŞY, Cansu DÜ, Kaşifoğlu T, Korkmaz C. The role of MEFV mutations in the concurrent disorders observed in patients with familial Mediterranean fever. European Journal of Rheumatology. 2016;3 (3):118-121.

Disclosure of Interest: None declared

DOI: 10.1136/annrheumdis-2018-eular.2825

\section{AB1118 PROCALCITONIN DIFFERENTIATES INFECTION FROM ACTIVE DISEASE IN PATIENTS WITH JUVENILE IDIOPATHIC ARTHRITIS (JIA)}

R. Trachtman ${ }^{1}$, E.T. Murray ${ }^{2}$, N. Pan ${ }^{1}$, S.S. Toussi ${ }^{1}$, M.E. Nellis ${ }^{3}$, J. Szymonifka ${ }^{2}$ S.F. Taber ${ }^{1}$, A.B. Adams ${ }^{1}$, K.B. Onel ${ }^{1}$, L.A. Mandl ${ }^{1} .{ }^{1}$ Hospital for Special Surgery/ Weill Cornell Medicine; ${ }^{2}$ Hospital for Special Surgery, ${ }^{3}$ Weill Cornell Medicine, New York, USA

Background: Patients with JIA often present with signs and symptoms suggestive of infection. However, differentiation of infectious from non-infectious presentation in routine clinical care is challenging. Procalcitonin (PCT) is a serum biomarker elevated in the setting of bacterial infection, but whether it can reliably differentiate infection from disease flare in patients with JIA is unknown. ${ }^{1}$ Objectives: To test the hypothesis that PCT levels will differ between active JIA quiescent JIA, bacteremic patients and healthy controls.

Abstract AB1118 - Table 1. Patient Characteristics

\begin{tabular}{|c|c|c|c|c|}
\hline & $\begin{array}{c}\text { Active Untreated } \\
\text { JIA } \\
(n=12)\end{array}$ & $\begin{array}{c}\text { Quiescent } \\
\text { JIA } \\
(n=15)\end{array}$ & $\begin{array}{c}\text { Healthy } \\
\text { Controls } \\
(n=16)\end{array}$ & $\begin{array}{c}\text { Bacteremic } \\
\text { Patients } \\
(n=5)\end{array}$ \\
\hline $\begin{array}{l}\text { Age, years } \\
\text { (median, IQ } \\
\text { range) }\end{array}$ & $\begin{array}{c}9.0 \\
{[2.4-12.8]}\end{array}$ & $\begin{array}{c}14.5 \\
{[9.9-17.4]}\end{array}$ & $\begin{array}{c}14.4 \\
{[13.9-15.5]}\end{array}$ & $\begin{array}{c}1.1 \\
{[0.8-1.8]}\end{array}$ \\
\hline $\begin{array}{l}\text { Male Gender } \\
\text { Race }\end{array}$ & $5(41.7 \%)$ & $3(20.0 \%)$ & $6(37.5 \%)$ & $3(60.0 \%)$ \\
\hline $\begin{array}{l}\text { Caucasian/ } \\
\text { White }\end{array}$ & 7 (58.3\%) & 14 (93.3\%) & 12 (75.0\%) & $2(50.0 \%)$ \\
\hline AA/Black & 1 (8.3\%) & $0(0.0 \%)$ & $3(18.8 \%)$ & $1(25.0 \%)$ \\
\hline Asian & $3(25.0 \%)$ & $1(6.7 \%)$ & $0(0.0 \%)$ & $1(25.0 \%)$ \\
\hline Other & $1(8.3 \%)$ & $0(0.0 \%)$ & $1(6.3 \%)$ & $0(0.0 \%)$ \\
\hline $\begin{array}{l}\text { Hispanic } \\
\text { Ethnicity }\end{array}$ & $2(16.7 \%)$ & 2 (13.3\%) & $1(6.3 \%)$ & $1(20.0 \%)$ \\
\hline $\begin{array}{l}\text { Private } \\
\text { Insurance }\end{array}$ & 7 (58.3\%) & 14 (93.3\%) & 14 (87.5\%) & $4(80.0 \%)$ \\
\hline
\end{tabular}

Abstract AB1118 - Table 2. Laboratory Data

\begin{tabular}{|c|c|c|c|c|c|}
\hline & $\begin{array}{c}\text { Active } \\
\text { Untreated JIA } \\
\quad(n=12)\end{array}$ & $\begin{array}{c}\text { Quiescent } \\
\text { JIA } \\
(n=15)\end{array}$ & $\begin{array}{l}\text { Healthy } \\
\text { controls } \\
(n=16)\end{array}$ & $\begin{array}{c}\text { Bacteremic } \\
\text { patients } \\
(n=5)\end{array}$ & $\begin{array}{c}\mathrm{p}- \\
\text { value }\end{array}$ \\
\hline $\begin{array}{l}\text { WBC (mean, } \\
\text { SD) }\end{array}$ & $8.9 \pm 4.4$ & $7.7 \pm 1.6$ & $6.7 \pm 1.7$ & $13.1 \pm 12.1$ & 0.06 \\
\hline $\begin{array}{l}\text { ESR } \\
\text { Normal<10 } \\
\text { (median, IQR) }\end{array}$ & $\begin{array}{c}6.0 \\
{[4.0-46.0]}\end{array}$ & $\begin{array}{c}8.0 \\
{[5.0-10.0]}\end{array}$ & $\begin{array}{c}8.0 \\
{[5.0-10.0]}\end{array}$ & $\begin{array}{c}43.0 \\
{[20.0-66.0]}\end{array}$ & 0.18 \\
\hline $\begin{array}{l}\text { CRP } \\
\text { Normal<1 } \\
\text { (median, IQR) }\end{array}$ & $\begin{array}{c}0.27 \\
{[0.12-6.48]}\end{array}$ & $\begin{array}{c}0.31 \\
{[0.16-2.65]}\end{array}$ & $\begin{array}{c}0.44 \\
{[0.12-1.85]}\end{array}$ & $\begin{array}{c}16.63 \\
{[7.76-25.68]}\end{array}$ & 0.067 \\
\hline $\begin{array}{l}\text { РCT } \\
\text { (median, IQR) }\end{array}$ & $\begin{array}{c}0.00 \\
{[0.00-0.00]}\end{array}$ & $\begin{array}{c}0.00 \\
{[0.00-0.00]}\end{array}$ & $\begin{array}{c}0.00 \\
{[0.00-0.00]}\end{array}$ & $\begin{array}{c}5.78 \\
{[4.26-52.00]}\end{array}$ & $<0.001$ \\
\hline
\end{tabular}

Methods: From 10/16-4/17, consecutive children 6 months - 18 years with a) active untreated JIA b) quiescent JIA and c) healthy pre-surgical candidates were recruited from a musculoskeletal specialty hospital. JIA was defined according to ILAR criteria. Patients with active JIA despite treatment were excluded, to avoid 
confounding by treatment. Consecutive bacteremic patients were identified from an associated paediatric intensive care unit over the same period. Descriptive statistics and univariate logistic analyses were performed as appropriate.

Results: Patient characteristics are summarised in Table 1; bacteremic patients were younger. PCT was elevated in bacteremic patients, and was undetectable in all other subjects (Table 2). There were trends towards higher ESR and CRP in bacteremic patients, but these were not statistically significant.

Conclusions: Serum PCT levels appear to be a reliable biomarker to distinguish infection vs. active JIA at presentation, and can aid in directing therapy. However, PCT does not appear useful to assess disease activity in JIA. Further studies are needed to assess utility of serum PCT measurement in differentiating JIA flares from less severe infections.

\section{REFERENCE:}

[1] Milcent K, et al., "Use of Procalcitonin Assays to Predict Serious Bacterial Infection in Young Febrile Infants," JAMA Pediatrics 170, no. 1 (2016): 6269; Mohsen A, et al., "Predictive Values for Procalcitonin in the Diagnosis of Neonatal Sepsis," Electronic Physician 7, no. 4 (2015): 1190-95.

Disclosure of Interest: None declared

DOI: 10.1136/annrheumdis-2018-eular.7238

\section{AB1119 CLINICAL, THERAPEUTIC CHARACTERISATION AND TIME TO ACHIVE REMISSION ANALYSIS OF A COLOMBIAN COHORT WITH JUVENILE IDIOPATHIC MYOPATHY}

R. Fuentes ${ }^{1}$, M. Cañola ${ }^{1}$, J.C. Diaz-Coronado ${ }^{2}$, A. Rojas-Villarraga ${ }^{2}$,

D. Hernandez-Parra ${ }^{2}$, P. Perez-Estrada ${ }^{2}$, J.C. Salazar-Uribe ${ }^{3}$, R. Pineda-Tamayo ${ }^{2}$

${ }^{1}$ Rheumatology Department, ${ }^{2}$ Clinical Research, Artmedica; ${ }^{3}$ National University of Colombia, Medellin, Colombia

Background: The clinical characteristics of paediatric patients with idiopathic inflammatory myopathies difere from adutls in several aspects. Its clinical presentation can include amyopathic onset and the skin involvement has diferent charecteristics

Objectives: To describe a Colombian cohort with Juvenile Myositis (JM) recruited in a rheumatology facility.

Methods: A cross-section retrospective research with data collected between 2014 and 2017 from a population diagnosed before 16 years of age with Idiopathic Myopathy according to Peter and Bohan criteria and followed up for at least six months. Kaplan-Meier curves were performed to analize time to achieve remission.

Results: Out of 37 patients, one was excluded for having a dystrophy myopathy gene, $73 \%$ fulfilled definitive and $16 \%$ probable Bohan and Peter criteria; most patients were female $75,8 \%,{ }^{28}$ with mean age of onset 7,2 years, and clinical remission was achieved on average at 4 years of disease. There was high prevalence of Gottron's sign and papules (89\%), Heliotrope rash (62\%) and Calcinosis (37\%). Other involvements are described in Table 1. Antinuclear antibodies were positive in $52 \%$. Electromyography (EMG) was positive for myopathy in $39 \%$ of the patients. Biopsy was compatible with myopathy in $10 \%$ and was negative in $32 \%$ of the patients. The most common treatment was metrothexate $(91 \%)$ followed by antimalarials (72\%) and corticoids (56,7\%). Medication used in severe forms included Cyclophosphamide (5\%), Rituximab (16\%) and IV Immunoglobulin $(5 \%)$. Kaplan-Meier curves showed an earlier time to remmision in patients with Gottron sign compared to patients without them (HR:8,25 HR Cl95\%IL:1,07663,$3 ; p=0042$ and in childrens younger than 15 years compared to older patients (HR: 2,529 HR95\%IL: 1,084-5,901, p: 0,039).

Abstract AB1119 - Table 1. Clinical characteristics of Colombian patients with JM.

\begin{tabular}{lcc}
\hline $\begin{array}{l}\text { Cahracteritstics in JM } \\
\mathbf{n}=\mathbf{3 7}\end{array}$ & $\mathbf{N}$ & $\%$ \\
\hline Symmetrical muscle & & 72,97 \\
weakness & 27 & 89,19 \\
Gottron's papules & 33 & 62,16 \\
Heliotrope rash & 23 & 37,84 \\
Calcinosis cutis & 14 & 16,22 \\
Gastrointestinal involvement & 6 & 10,81 \\
Pulmonary involvement & 4 & 24,32 \\
Articular involvement & 9 & 24,32 \\
Amyopathic & 9 & 37,84 \\
ANA(+) & $14 /$ & \\
& 27 & 24,32 \\
EMG Myopathic changes & $9 / 23$ & 10,81 \\
Biopsy-proven myopathy & & 32,43 \\
Positive & 4 & \\
Negative & 12 &
\end{tabular}

Conclusions: Our results agreed with those obtained in other multi-centred studies including latin america that evaluated clinical and therapeutic characteristics in children with myopathy, Gottron's sign and papules being the most common findings and with high rates of calcinosis and joint involvement. There was a significant difference between remission lapse in patients younger than 15 years compared to older ones.

\section{REFERENCE:}

[1] , D. Guseinova, et al. Comparison of clinical features and drug therapies among European and Latin American patients with juvenile dermatomyositis. Clinical and Experimental Rheumatology 2011; 29: 117-124

Disclosure of Interest: None declared

DOI: 10.1136/annrheumdis-2018-eular.3686

\section{AB1120 THYROID HORMONE CONCENTRATIONS IN CHILDREN WITH JUVENILE IDIOPATHIC ARTHRITIS FROM A SINGLE TERTIARY REFERRAL CENTRE}

R. Eremciuc ${ }^{1,2}$, N. Revenco ${ }^{1,2} .{ }^{1}$ Paediatric Department, State University of Medicine and Pharmacy "Nicolae Testemitanu"; ${ }^{2}$ Paediatric Rheumatologic Unit, Scientific Research Institute for Mother and Child Health Care, Chisinau, Moldova, Republic of

Background: Despite mounting evidence linking both endocrine disorders and rheumatic diseases, there is a lack of studies investigating any association between the prevalence and clinical characteristics of thyroid disorders and juvenile idiopathic arthritis (JIA)

Objectives: The aim of this study is to assess the prevalence of abnormalities in thyroid function in patients with JIA, and to investigate the possible association between this endocrine disorders and specific disease activity markers.

Methods: Thirty patients diagnosed with JIA according to the Internationa League of Association for Rheumatology were screened for thyroid diseases. We performed stratified analyses by sex, age, subtype of JIA, disease duration, the Juvenile Arthritis Disease Activity Score (JADAS-71), clinical peculiarities, laboratory values and ultrasound examination of thyroidal gland.

Results: Our results revealed that $67 \%$ of patients were girls. The mean age of the studied group was $127,56 \pm 8,8$ months, the median age at diagnosis was $74,33 \pm 8,49$ months and the median disease duration was $50,83 \pm 9,33$ months The most frequent types of JIA were oligoarticular (40\%), polyarticular negative RF (34\%) and systemic (20\%). The median JADAS-71 score was $16,91 \pm 1,64$ [range values from 5 to 34]. The status of the thyroid function in those patients was euthyroidism. Contrary to other findings in the literature, a high free triiodo thyronine was recorded in $33 \%$ of cases. However, specific antibodies as antithyroglobulin and antithyroid peroxidase were not detected in any patients. The ultrasound examination of thyroidal gland revealed abnormalities in $30 \%$ cases most of them cystic changes $(26,6 \%)$ and hypo-echogenicity $(23,33 \%)$. In 2 cases were detected 2 thyroid nodules. Furthermore, 2 patients presented mean thyroid volume above 2SDS according their age reference values. An increased vascular flow pattern on Doppler examination of thyroidal gland was found in $10 \%$ cases Correlation and regression analysis showed low age at diagnosis and JADAS-71 score (more than 20) to be predictors for those thyroid disorders.

Conclusions: The goal of early identification of endocrine comorbidities in rheumatic diseases is to prevent and limit the clinical disease impact. The identification of autoimmune diseases in preclinical stage secondary to juvenile idiopathic arthritis allow a better disease control and quality of life.

\section{REFERENCES:}

[1] Tronconi E., Miniaci A., Pession A., The autoimmune burden in juvenile idiopathic arthritis, Italian Journal of Pediatrics, 2017, 43:56.

[2] Elnady B.M., et all., Prevalence and clinical significance of nonorgan-specific antibodies in patients with autoimmune thyroiditis as predictor markers for rheumatic diseases, Medicine, 2016, 95:38 (e4336).

[3] Robazzi T.C., Adan L.F., Autoimmune thyroid disease in patients with rheumatic diseases, Rev Bras Reumatol, 2012; 52 (3): 417-430.

Disclosure of Interest: None declared

DOI: 10.1136/annrheumdis-2018-eular.7293

\section{AB1121 EVALUATION OF CASES DIAGNOSED WITH CRMO; SINGLE CENTRE EXPERIENCE}

S. Cekic, Y. Karali, S.S. Kilic. Uludag University, Bursa, Turkey

Background: Chronic recurrent multifocal osteomyelitis (CRMO); is a rare autoinflammatory bone disease characterised by recurrent, sterile inflammatory 